\title{
Fogo Cruel em Lua de Mel: tragicomédia existencial
}

\author{
BENE MARTINS
}

This article is devoted to the analysis of a play created by the actor Cláudio Marinho, from Cia. Scenic Faith. A proposal of International Colloquium of Theatre Critics: Launching Dialogues: Critics of Art of Performance and Public Sphere, proposes to reactivate the dialogue with who is writing, creating the plays and of course with who is directing, and spectators. From my point of view critical studies about artistic realizations require to indicate the moment for enunciation, when you talk, for whom and why a specific event to be staged is designated, so-called, post-staging. Cruel Fire during the Honey-Moon (1976) highlights one couple: he is a bohemian, irreverent poet, she is an ultra-religious social assistant, whose dialogues focus on a play of contradictions with an aim to expose existential questions, such as what is the meaning of life, where are my dreams, my wishes? Both, faced by the inevitable death, undergo surprising changes. Conflicts vary between drama and comedy exploring the nuances of reality, imagery, place for divergences, and practice of imagination. Due to the peculiarities of theatre text, the conception of a director I identified elements which are used to put characters to stage, performance and involvement of actors into the characters and furthermore to demonstrate the belief of the author of the play Nazareno Tourinho in a change of a person thanks to the theatre.

CRITICS / PLAY / PERFORMANCE / TRAGICOMEDY / NAZARENO TOURINHO

A crítica é um discurso sobre o discurso. ROLAND BARTHES

O Colóquio Internacional de Crítica de Teatro Lançar Diálogos: Crítica de Artes do Espectáculo e Esfera Pública propôs reatar diálogo com quem escreve, quem produz espetáculos e, naturalmente, com encenadores e com espectadores; aproximar o fazer teatral e o público em geral; promover espaço de encontro e exposição de trabalhos voltados à crítica 
de espetáculos. Assim, para estabelecer, ampliar contatos e divulgar a produção de um dos mais importantes dramaturgos da Amazônia brasileira, Nazareno Tourinho, apresento breve análise crítica do espetáculo Fogo Cruel em Lua de $\mathrm{Mel}$ (1976), uma das quatorze peças do autor ${ }^{1}$. Destaco, antes, alguns apontamentos sobre o papel do crítico.

O espetáculo foi dirigido por Cláudio Marinho, ator e diretor da Cia. Fé Cênica ${ }^{2}$. Neste texto, a partir das especificidades da peça-espetáculo, em diálogo com o diretor, identificarei elementos utilizados para pôr as personagens em cena, o desempenho e envolvimento dos atores com as personagens, e chamo atenção para uma das características do autor da peça, qual seja, a de expor as contradições humanas, e acreditar na mudança das pessoas, por meio do teatro.

Para iniciar a escrita, teço considerações sobre estudos críticos, a meu ver, indispensáveis às apreciações de obras artísticas. Em primeiro lugar, o cuidado de quem escreve. Este deveria afirmar o lugar da enunciação, ou seja, explicitar de onde fala, para quem fala e porque elegeu determinado evento para pôr em cena, desta feita, sob escrita apreciativa, pós-encenação.

Crítica, palavra temida, mas presente em todos os atos de nossas vidas, verbalizada, insinuada por olhares e gestos, ou escrita; apreciações, positivas ou negativas sobre nossos comportamentos e ações, ocorrem a todo momento. O temor e receio de ser avaliado é reação comum, creio que em todos os segmentos da humanidade. Mas não há como escapar, estamos expostos a juízos de valor, seja ao realizarmos algo, seja ao falarmos, em quaisquer circunstâncias, olhares críticos e julgamentos pairam sobre nossas ações. Temor compreensível, mas inevitável. Pois bem, há muito se afirma que a crítica e as artes em geral estão em crise.

Crise por ter perdido espaço nos grandes jornais impressos; crise por falta de preparo de quem escreve; crise por falta de frequência de espectadores, especializados ou não, aos espaços artísticos. O teatro e, consequentemente, a crítica em crise, sempre. As benditas crises, ora em ascendência, ora em declive, agonizantes. Benditas crises, sim, porque, ricas de possibilidades outras de criação, tanto de propostas estéticas,

1 Bene Martins (org.) Peças Teatrais de Nazareno Tourinho, Belém, CEJUP, 2014 (obra completa).

2 Cia. Fé Cênica, criada em 2007, em São Paulo. Esta peça foi a primeira montagem da Companhia, e a primeira direção de Cláudio Marinho. Duas temporadas no espaço Casa, Café e Teatro, uma temporada no Teatro Commune e outra no Teatro Bela Vista, todos os espaços em São Paulo. Em Belém apresentamos no Espaço Cuíra e no SESC Boulevard. Foi um ciclo de oito anos que encerrou no final de 2014, no Teatro Livraria da Vila, no Shopping JK Iguatemi-SP. (http://oanticamarada.blogspot.com.br/2013/01/fogo-cruel-em-lua-de-mel-da-cia-fe.html). 
quanto a reações de estranhamento às diferentes encenações. Reações ora de aceite, ora de rejeição ao novo. Mas vale ressaltar que, graças às crises, ao esgotamento de tendências repetidas, é que surgem outros olhares sobre peças, às vezes, consideradas ultrapassadas, fora de época e que, encenadas sob novos enfoques, desvendam aspectos ainda não percebidos nas montagens anteriores.

Bernard Dort (1960) afirma, em Leitura de Brecht, que cabe à arte desvendar imagens inteligíveis do mundo, ou seja, à semelhança de Brecht, chamar atenção para o que ainda não se vê, e para tal propósito, a «preocupação primordial de Brecht, não de deixar à posteridade mais uma obra de arte, mas antes de propor aos seus contemporâneos, recriadas pelas artes, imagens inteligíveis do mundo e do tempo em que viviam» (Dort, 1960: 9). A arte pela arte, nos moldes tradicionais apenas, não bastaria; inovações são primordiais, isto é, a partir do que está posto e saturado ou em crise, faz-se necessário reinventar, transformar, deixar algo relevante sobre o mundo que nos cerca, por meio da arte. Este é um dos pontos-chave da criação artística. Mas: «O que é preciso transformar? O todo, mas isso é fácil de dizer. E transformá-lo como? A partir de quê?» (Dort, 1960: 96, 97). Nazareno diria transformar a partir do teatro. Ainda, Dort: «Ao transformar o mundo, transformai-vos!» (Dort, 1960: 95). Esta é a aposta de Nazareno Tourinho, ele acredita que o teatro pode transformar as pessoas e a sociedade.

Talvez uma das dificuldades do exercício da crítica seja decorrente desse leque de possibilidades de encenação, hoje mais aberto a estéticas outras. Como escrever sobre tão variadas propostas, inúmeras alternativas de montagem, recursos avançados da tecnologia; como acompanhar tais evoluções? Como assistir a tamanha diversidade de espetáculos? Qual seria a função da crítica? Seria a interlocução com os pares das artes do espetáculo ou a de expandir o diálogo com o público em geral? Quem escreve sobre teatro, há que, no mínimo ser frequentador assíduo, conhecedor das tendências, referências, estudos da área e mais, ver o espetáculo criticado mais de uma vez! Quantos o fazem? E, mais ainda, a crítica não deve ser considerada o juízo final sobre determinado espetáculo! Pois, por mais preparado, quem escreve, escreve a partir da sua concepção, vivências, capacidade, repertório cultural, preferências pessoais. Não há escrita inocente, por assim dizer.

O crítico não é, ou não deveria ser, a pessoa que explica a peça-espetáculo, como se o espectador não fosse capaz de realizar a própria leitura sobre o que leu, assistiu. Ao crítico, caberia o papel principal de incitar a ida ao teatro, a partir de textos bem elaborados, não de opinião 
apenas; escrever de maneira a despertar o interesse de quem lê; assinalar outras portas de entrada e de entendimento; chamar a atenção para o que estaria nas entrelinhas do texto, de maneira que o espectador possa ir além da recepção acionada somente pela sensibilidade. Esta é importante, mas pode ser ampliada, ao exercitar-se o olhar atento, questionar, ler com prazer, com discernimento, abrir o leque de leituras. Rine Leal faz distinção entre o espectador comum e o crítico:

O que, então, distingue um espectador comum de um espectador crítico? Na falta da ingenuidade que o seu trabalho supõe, neste segundo olhar (The mind's eye de que fala Hamlet) que nos faz ver além das aparências da cena, e ao conceituar o teatro como uma situação da cultura e não um entretenimento ou negócio, ainda que possua ambas as coisas. O resto, bem, o resto é conhecimento do teatro, habilidade literária, sensibilidade, inteligência e leitores. (Leal, 1967: 11)

Ao crítico, não basta achar que escreve bem e não ser compreendido por quem o lê, ou somente assinalar opiniões vagas, a exemplo dos que afirmam: o espetáculo é confuso, a proposta não foi clara o suficiente; impressões gerais restringem o esclarecimento. Há que se demonstrar qual ênfase, quais elementos serão analisados no texto sobre determinado espetáculo; explicitar, por exemplo, a linha de trabalho dramatúrgico da encenação, o desempenho dos atores, o aspecto visual, a composição do cenário, o figurino, a iluminação, entre outros elementos da cena. Caberia ao crítico, além do sucintamente mencionado, a consciência de que sua escrita deve chegar ao espectador-leitor, de maneira a fazê-lo transbordar vagas opiniões, perceber o espetáculo em sua inteireza, ou melhor, em suas lacunas, perceber outras alternativas de montagem; confiar na capacidade do espectador para entender e envolver-se com o mundo do teatro. Assim, segundo Olga Reverbel:

Pouco a pouco, as expressões limitadas, como «gusto» e «não gusto», isto é, os julgamentos sumários, perdem o sentido; os alunos analisam os trabalhos dos companheiros com maior propriedade, explicando os «porquês». Na medida que se cria o hábito de se criticar, os alunos se exprimem cada vez mais espontaneamente. (Reverbel, 1997: 30)

O crítico pode ou deveria ser o mediador, o interlocutor das obras com o público em geral, não impor gosto, opinião, mas provocar o espectador 
a buscar o texto da peça encenada, não ler apenas a crítica. Esta deve ser estimulante, não determinante. Caso contrário, reiterar-se-á o que T. S. Eliot constatou em 1999, a ênfase da leitura sobre a obra, em vez da obra em si. «Naturalmente, a multiplicação das obras e dos ensaios críticos pode criar, e vi a coisa produzir-se, o gosto depravado de ler o que se escreveu sobre as obras de arte, mais do que ler as próprias obras; pode fornecer uma opinião, em vez de educar o gosto» (Eliot, 1999: 49, 50). Egberto Garcia Abreu, em Crítica ou Críticos: Um Dilema do Teatro, enfatiza a necessidade da vivência no mundo do teatro para a formação do pensar crítico.

A crítica acompanha o exercício cotidiano da criação teatral. Deixa sinais de seus passos em uma ou outra direção, mas estes sinais não devem ser vistos como referências inequívocas ou infalíveis. São registros que foram e continuarão sendo resultado dos olhares pessoais daqueles que, a partir de diferentes posições, leram, concluíram, instrumentalizaram, descobriram os possíveis alcances das imagens teatrais, não importando seu suporte nem a forma concreta com que são apresentadas ao espectador ou ao leitor. (Abreu, 2012: 1)

Considerações sobre crítica esboçadas, com receio de não as cumprir, inicio análise do espetáculo, Fogo Cruel em Lua de Mel, do encenador Cláudio Marinho3 ${ }^{3}$ Cláudio optou por seguir à risca o texto e suas rubricas, o que resultou em trabalho de comunicação imediata com o público, no sentido de que não causou estranheza, pois não rebuscou o cenário, nem alterou o texto, foi fiel à trama textual. Uma tragicomédia, segundo Nazareno Tourinho. A opção do encenador, talvez cômoda, deve-se ao compromisso, respeito, admiração por Nazareno Tourinho, tanto é que a remontagem da peça foi em comemoração dupla, oito anos da Cia. Fé Cênica e oitenta anos de Nazareno. Ou seja, seria oito ou oitenta, optou por oitenta, isto é, não contrariar os direcionamentos do autor e a familiaridade do público com esse tipo de espetáculo, sem grandes elaborações, o que não desmerece o resultado da montagem.

Fogo Cruel em Lua de Mel põe em cena o casal, Gil e Elza. Ele poeta, boêmio, irreverente, ateu; a esposa, assistente social ultrarreligiosa. Recém-casados, após onze anos de namoro, em sua primeira noite, em apartamento de hotel. Ele prepara-se para o grande momento; ela, 
reticente, persiste em cobrar mudança de comportamento do irreverente marido. Para desespero de Gil, Elza confessa que fizera promessa a Santo Antônio, se casasse com ele, na primeira noite de casados, não aconteceria a relação sexual, tão esperada. Aqui, a primeira contradição da personagem, desejava casar, mas não consumar o fato, não na primeira noite, para desespero do ansioso e apaixonado marido. Assim o enredo segue, entre o ir e vir das emoções do casal.

Cláudio explica a proposta do espetáculo.

Já tínhamos a vontade de colocar o ator no limiar entre o riso e o choro, entre a dor e o prazer. Buscamos sempre a contradição, a valorização do conflito, que alimenta a dramaturgia. O texto de Nazareno Tourinho serve bem para este propósito porque desnuda a alma e nos faz pensar sobre as múltiplas possibilidades de ser e estar. Por isso continua em nosso repertório desde que o grupo existe (Cláudio Marinho) ${ }^{4}$

Em Fogo Cruel em Lua de Mel, o diálogo do casal expõe a situação, a seguir vem a peripécia, a surpresa, no momento em que Elza revela que não poderá entregar-se a ele na noite de núpcias, devido à promessa feita ao santo casamenteiro. Os diálogos são claros, concisos, não há embromação, é um prêmio para os atores que conseguem entrar no clima do enredo. O casal é vivido pelo ator Geraldo Machado 5 e Viviana Bernard. Ele, ator paulistano, visivelmente mais à vontade na pele do marido, às vezes, atropela as falas, rápido de mais, mas consegue alterar o ritmo, entrega-se ao jogo, dá vida às expressões desesperadas, reflexivas do marido frustrado. A atriz, ao contrário, demonstra nervosismo, a personagem, menos expansiva que a de Gil, deveria enfatizar a tensão, o conflito maior, manter-se fiel à promessa ao Santo ou entregar-se ao enlace amoroso. Apesar dessa falha, o resultado do espetáculo é bom, embora o texto dramático exigisse mais gestualidade, mais emoção. A preocupação em dizer o texto na íntegra talvez tenha prejudicado o desempenho da atriz.

Cláudio Marinho destaca a ênfase dada ao texto tragicômico e ao cenário clean, conforme rubricas da peça.

Nazareno propõe situações e falas que buscam o riso na situação trágica. Buscamos valorizar isto na atuação. Ele quer amar, ela continua presa a

4 Fotos: http://vejasp.abril.com.br/atracao/fogo-cruel-em-lua-de-mel.

5 Geraldo Machado (1966-2015). O primeiro ator da Cia. Fé Cênica. Inesquecível! Artista com alma de criança. Brilha agora na memória de quem o viu em cena. 
uma promessa. Na nossa pesquisa, o que mais nos provocava, naquele momento, era a pergunta «o que faço diante da morte?» [...] Dediquei atenção muito mais ao texto e às possibilidades de nuances e o trabalho do ator neste limiar entre o drama e a comédia. Fui influenciado pelo método de atuação para cinema desenvolvido pela Fátima Toledo ${ }^{6}$ [...] Diante de tanta vontade de mergulhar no texto e nos atores, os outros elementos cênicos foram tratados como acessórios. O cenário branco como sugere o texto (simboliza a pureza que Elza busca), a sonoplastia recorre às constantes intervenções do personagem radialista (na nossa montagem poderíamos adaptar, sugerir recursos mais modernos, mas optamos em deixar as referências retrô). De verdade, pra nós estes elementos não nos chamavam a atenção. Buscávamos a agonia e a alegria de viver. (Cláudio Marinho) ${ }^{7}$

Gil, ao saber da absurda promessa da esposa, enfurece, blasfema contra a fé, contra o Santo Antônio. Elza não cede, permanece abraçada ao santo. A noite que seria de núpcias torna-se uma longa e exaustiva discussão sobre valores individuais. Ele cético; ela quer que ele mude, passe a acreditar e respeitar os princípios religiosas dela. Retaliações mútuas, não há acordo entre eles e, para complicar a situação, acontece o incêndio no hotel. O que fica claro no texto e no espetáculo é o jogo de contradições a expor questões existenciais, comuns ao ser humano, desde sempre: qual o sentido da vida? Onde estão meus sonhos, meus desejos?

Para Nazareno e suas personagens, neste caso, Gil, o ser humano tolhido em sua capacidade de imaginar seria um ser menos feliz. Uma das características da imaginação, para o autor, seria a de que ela

Despreza o raciocínio, o raciocínio é traiçoeiro, só serve para enredar a gente da teia do artificial, do calculado, não conduz a nada de grande e de belo [...] a imaginação é diferente. Elza, a imaginação corta as correntes do impossível e nos solta, no espaço azul do horizonte... Abre a porta da imaginação com chave da loucura, rebenta, Elza, rebenta!!! (Gil, em Fogo Cruel em Lua de Mel)

6 Em 2012 concluí Curso de Jornalismo Cultural lato sensu em Jornalismo Cultural na FAAP, com a monografia Alma e Suor: a influência da preparadora de elenco Fátima Toledo no cinema brasileiro. Esta pesquisa me deu a oportunidade de frequentar o estúdio Fátima Toledo, como observador das aulas. Pude entrevistar professores, alunos, diretores de cinema. Com certeza esta pesquisa, que era focada na atuação para cinema, influenciou o processo em Fogo Cruel em Lua de Mel.

7 Entrevista realizada por e-mail, a 17 de maio de 2016. 
Nesta peça, os envolvidos passam por transformação surpreendente! Entre o trágico e o cômico, Nazareno tece, reelabora, fantasia, no sentido de dramatizar os fatos e uma situação ou notícia insípida, por exemplo, passa a ter sabor ou fim trágico. Porque poeticamente estruturada em cenas, ele conta histórias das personagens/espelhos de vivências. Todas as personagens têm razões justificadas para suas existências. Não há julgamento, nos textos do autor há espaço para vozes ignoradas, todos são elevados à categoria do humano, com suas qualidades e defeitos, independente de classe social ou profissão. $O$ encenador procurou enfatizar as cenas em que as contradições explícitas, nas falas e comportamento das personagens, são mais evidentes e os coloca em posição trágico-cômica.

Assim, numa espécie de jogo de cão e gato, ele ataca, ela esquiva-se, há um jorrar de palavras, ora acusatórias, ora defensivas entre o casal; logo após, o entrecho, outra reviravolta ocorre quando se veem presos no hotel incendiado. Núpcias duplamente interrompida: pela repressão do desejo e pelo fogo a arder as paredes do hotel, metáfora da efervescência de desejos guardados, duplas chamas: interiores e exteriores!

O fogo arde, as possibilidades de sobrevivência diminuem. Mas onde estão os sonhos? Onde estão os desejos? Onde está a verdade? Onde está a verdade (do ator, principalmente. A verdade do ator, que foi a matéria-prima para este trabalho). Aqui pude observar no público reações diversas. Em determinadas sessões a plateia queria rir, em outras a plateia queria chorar. Observei isto na primeira temporada que durou quase um ano, com uma sessão semanal. (Cláudio Marinho) ${ }^{8}$

$\mathrm{Na}$ sequência do texto, que primeiro é sustentado na comédia da situação e depois no conflito dos personagens diante da possibilidade da morte, vem o momento em que Elza e Gil param de brigar para olhar para si mesmos. Novamente, as personagens precisam transitar para emoções mais profundas. Solidão. E novamente a pergunta «o que faço agora diante da morte?» ou «o que fiz do meu tempo?». (Cláudio Marinho) ${ }^{9}$

Além das qualidades inerentes ao texto literário escrito para o teatro, os diálogos das personagens primam pela clareza, pela reflexão estético-filosófica. $\mathrm{O}$ autor expõe o ser frágil e fragilizado por suas inseguranças, 
inquietações, fantasias, fantasmas. A maioria das personagens apresenta senso crítico aguçado, tecem críticas ao sistema e às injustiças no cotidiano dos povos. A exemplo do diálogo do casal da peça Amor de Louco nunca É Pouco, quando discutem suas idiossincrasias:

ELA

Você me deixa confusa, embaraçada; me diga uma coisa: além de arte dramática você estudou Psicologia, Psicanálise?

ELE

Estudei. Só que não estudei as pessoas em livros, estudei nelas mesmas... Não estudei por fora, estudei por dentro... Aliás, eu não estudei, eu vivi. Quase todos os tipos humanos eu já vivi no palco. Já senti na minha pele, nos meus nervos, nas minhas emoções, no meu cérebro. (Amor de Louco nunca É Pouco, 1976)

A dramaturgia de Nazareno é pensada e escrita de maneira visceral, não é aquela escrita de gabinete, é o traçar de linhas pautadas na pesquisa, na observação e nas vivências de pessoas envolvidas em situações críveis. Ainda se pode afirmar que, à semelhança de Bertolt Brecht, Nazareno também comunga da ideia de que «o mundo de hoje pode ser reproduzido, mesmo no teatro, mas somente se for concebido como um mundo suscetível de modificação» (Brecht, 2005: 21). As peças de Nazareno apresentam um tom de aposta no ser humano. Essa é uma das razões da boa acolhida e recepção por parte dos espectadores. As pessoas identificam-se de tal maneira com esses textos do autor que, cada reencenação é prestigiada pelo público em geral. A exemplo das remontagens das peças: Fogo Cruel em Lua de Mel e Nó de Quatro Pernas ${ }^{10}$, em 2012.

Outra tônica dos textos de Tourinho é o jogo com as oposições entre bem e mal; pureza e pecado; vício e virtude; sagrado e profano; lucidez e loucura. Em Fogo Cruel em Lua de Mel, o protagonista afirma que loucura é revelação, conforme fragmentos do diálogo do casal, ele considerado bom vivant; ela extremamente conservadora:

\section{[...] ELZA}

De fato, que diria, vendo você afiançar que jamais botaria na boca um pingo de álcool. 
GIL

(Encosta a garrafa na imagem.) Eis aí dois símbolos, para você que admira simbolismos: o santo e a garrafa... a virtude e o vício... a pureza e o pecado... o céu e a terra... O teu santo e a minha garrafa... juntos, nos separando... [...] ELZA

Você é um maluco, ouviu? Um maluco!

GIL

Sou. Mas a minha loucura é mais honesta que a tua impostura. Experimenta você também enlouquecer, experimenta. A loucura é uma revelação. [...] Enlouquece você também, enlouquecer é sublime. Enlouquece comigo. (Gil, em Fogo Cruel em Lua de Mel)

Cláudio nota as divergências do casal. Para Gil, a loucura liberta. Elza, até então devota e recatada, na situação de desespero em que se encontram, à iminência da morte, induzida por seu marido, começa a refletir sobre o tempo investido em devoção e recato apenas. Gil, ao contrário, sempre aproveitou as coisas boas da vida. Mas, paradoxalmente, ele também em situação-limite, demonstra o quanto o ser humano pode surpreender, quando se dispõe a tirar as máscaras, a olhar para si sem receio do que verá. Este casal passa por uma transformação, ou melhor, uma inversão de comportamentos ante a morte que os aproxima de si mesmos.

Enquanto o casal discute acaloradamente, o edifício do hotel incendeia, literalmente, eles não têm saída. Gil entra em pânico e, num impulso, pede à Elza que reze para se salvarem. Outra contradição da personagem, até então, ateu debochado. Ao pedido surpreendente do marido, Elza nega-se a atender e diz para comportar-se como homem, reagir para escaparem à morte. Ambos surpreendem, ele, desesperado, confessa seus pecados e diz ter descoberto a razão e mistério da existência. Ela, ao contrário, arrependida de fugir aos prazeres da vida, tenta seduzir o marido, agora quer entregar-se, quer enlouquecer com ele, esquece da promessa ao santo. Ambos, frente ao inevitável, reveem seus valores.

Ele, repentinamente, convertido, recusa, não quer contato corporal, sexo seria pecado. Ambos ardem nas chamas do incêndio-inferno; ele implora por misericórdia; ela, por sexo. Embora tenha faltado um pouco mais de fé cênica, numa referência ao nome da companhia que prima pela boa atuação. A encenação conquistou público e foi elogiada pelo homenageado, aos oitenta anos de idade. O espetáculo flui, não há momentos cansativos, aliás, um dos pecadinhos da montagem, a preocupação em 
ser ágil, por vezes, encobriu o que poderia ser enfatizado em emoção, em ações mais viscerais, por assim dizer.

O momento em que Gil percebe a sua face sagrada, Elza enxerga sua condição humana. E é nesta «inversão de papéis», neste conflito que ressurge um tom de comédia. Elza se descobre uma mulher ardente e percebe nisso a santidade da existência. Gil enxerga Deus, o seu Deus (o sentido para aquele momento) [...] Geraldo Machado faleceu no início de 2015 e decidi encerrar a produção. Percebi que ele acompanhou todos os momentos da pesquisa e da inquietação proposta pela direção. Na última temporada, na última cena da peça, ele se ajoelhava e dizia que estava enxergando Deus. Os olhos dele me convenciam. (Cláudio Marinho) $)^{11}$

Sem querer entrar na interpretação metafísica ou fatalismo da existência, poder-se-ia deduzir das palavras do diretor, Cláudio Marinho, a respeito da morte do protagonista da peça que, a exemplo da personagem, o ator Geraldo Machado, foi quem passou pela transformação maior, a de passar deste plano da existência para outro.

Sempre parece que Nazareno quer julgar as personagens, mas, no meio do caminho de sua escrita (que alcança momentos de um lirismo arrebatador) ele as vai escutando, acalentando, namorando e, finalmente, amando e perdoando. Tenho de confessar que acho Nazareno uma figura enigmática: é espírita, assumidamente comunista e, como espera-se dos artistas verdadeiros, com uma obra que ultrapassa todas essas preferências. Não é à toa que foi comparado com Ariano Suassuna, um mestre da dramaturgia - arrisco dizer-mundial, outro que não ligava para «realismo socialista» ou coisa parecida. Bons tempos em que a esquerda contemplava o mundo e transformava isso em arte - nem sempre boa, nem sempre má, mas com sinceridade. Hoje, tudo virou sinopse acadêmica para jantares inteligentes (Cláudio Marinho) ${ }^{12}$. 
Sobre Nazareno Tourinho, Cláudio Marinho é preciso:

O que tenho a dizer sobre a dramaturgia de Nazareno Tourinho são três impressões fortíssimas que sempre causaram imenso prazer a este que vos escreve: um texto ágil como uma partida de pingue-pongue, monólogos capazes de consagrar atores e a extrema sensibilidade na construção de personagens que começam sempre como arquétipos e terminam desviscerados em assustadora humanidade. (Cláudio Marinho) ${ }^{13}$

Às três impressões de Cláudio Marinho, pode-se acrescentar inúmeras outras, entre as quais, veia poética, exercício da imaginação, pesquisa sobre o que escreve. Nazareno consegue, a partir de um fato corriqueiro do cotidiano, tecer uma trama envolvente, ágil, elegante, diálogos bem elaborados, rubricas fartas, de maneira que possibilita a encenadores iniciantes montarem suas peças, cuja estrutura é irretocável. Ao interromper a análise, cabe enfatizar que Nazareno escreve a partir de um compromisso assumido com a mudança sociocultural: «Eu escrevo pensando no efeito social das minhas peças. $\gg^{14}$ A dramaturgia de Nazareno é pensada e escrita de maneira a chegar ao povo, ele quer passar algo a mais, além da leitura da peça e do espetáculo. Ele deseja provocar reflexão, mudança nos modos de ser das pessoas. Nazareno, além da influência brechtiana, acredita realmente que a pessoa pode mudar, por meio do teatro também. Suas peças apostam na evolução, na transformação do indivíduo para melhor, sempre, desde que expostos a situações provocadoras de reflexão, e o teatro é um dos espaços propícios, também, a pausas pensativas e que estas induzam a mudanças significativas. Este é um dos papéis do dramaturgo, do teatro, das artes em geral, o de transformar a si, em primeiro lugar. Nazareno defende e escreve suas peças com esse propósito, o de mudar ações comportamentais do ser humano. 


\section{REFERÊNCIAS BIBLIOGRÁFICAS}

ABREU, Egberto Garcia (2012), «Crítica ou Críticos: um Dilema do Teatro», in Revista USP, 2 (12), p. 2. BRECHT, Bertolt (2005), Estudos de Teatro, Rio de Janeiro, Nova Fronteira. DORT, Bernard (1980), Leitura de Brecht, Lisboa, Forja Editora. ELIOT, T. S. (1999), Essais choisis, Paris, Seuil. LEAL, Rine (1967), En Primera Persona, Havana, Instituto cubano del libro. MARTins, Bene (org.) (2014), Peças Teatrais de Nazareno Tourinho, Belém, CEJUP. REVER beL, Olga (1997), Um caminho do teatro na escola, São Paulo, Scipione.

\section{BENE MARTINS}

Professora investigadora da Universidade Federal do Pará. Possui mestrado em Letras: Linguística e Teoria Literária pela Universidade Federal do Pará (1997) e doutoramento em Letras pela Universidade Federal de Minas Gerais (2004). É professora adjunta da Escola de Teatro e Dança e do programa de pós-graduação em Artes (PPGARTES) UFPA. Coordenadora do projecto de pesquisa «Memória da Dramaturgia Amazónida: Construção de Acervo Dramatúrgico». Pós-doutoranda em Estudos de Teatro, com ênfase em Dramaturgia, na Faculdade de Letras (Centro de Estudos de Teatro) da Universidade de Lisboa, 2015. 